\title{
Case Markers in Mongolian: A Means for Encoding Null Constituents in Noun Phrase and Relative Clause
}

\author{
Tseden Otgonsuren \\ Department of British and American Studies, Faculty of Humanities, School of Arts and Sciences, National University of Mongolia, Mongolia \\ E-mail: otgonsuren@num.edu.mn
}

Doi:10.7575/aiac.alls.v.8n.1p.17

URL: http://dx.doi.org/10.7575/aiac.alls.v.8n.1p.17
Received: 15/09/2016

Accepted: 17/12/2016

This paper was sponsored by Professor David Richard Pichaske's scholarship for the Ph.D. candidates of the Department of British and American Studies.

\begin{abstract}
This paper focuses on the capacity of the case markers in the Mongolian language, as a relative element, to generate any finite noun phrase or relative clause based on their syntactic function or relationship. In Mongolian, there are two different approaches to generate noun phrases: parataxis and hypotaxis. According to my early observation, if the noun phrase generated through the parataxis, is the complement of the postpositional phrase, the head word of the relevant noun phrase can be truncated. In other words, since this head noun is governed by case marker in its null form to generate the postpositional phrase, the head noun can be encoded. The second approach generates two different types of noun phrases in their structures: free structured and non-free structured noun phrases. Of them, the free structured noun phrase allows any syntactic transformations in their internal structure based on the senses of the case markers which denote a relation. That is to say, the null constituents in this type of noun phrases can be encoded to generate an extended alternative of the noun phrase and a relative clause.
\end{abstract}

Keywords: case marker, null constituent, head noun, noun phrase, relative clause, finite/extended alternative

\section{Introduction}

Almost all human languages have elements to denote a relation within "strings in a sequence" (N.Chomsky 2002).

These elements comprise either case markers (-iin, -d/-t, -aas, -aar, -tai, etc.) or postpositions (deer, door, ömnö, hoino, etc.) in Mongolian, which have the same functions as prepositions do in English, as for the languages with dominant SOV and SVO orders, respectively. If a language has no such grammatical element or "function word" (A.Radford 1998:37), or "grammatical word" (J.Miller 2002:35), the constituents are merely a collection of words with no comprehensive meaning and with no linear order as in (1).

(1) a. * Bid Bulgan aimag Saihan sum irsen
b. *We-NOM Bulgan province-NOM
c. * We came Saihan sum Bulgan province.
Saihan sum-NOM come-PST

If the genitive case marker (-iin) precedes Bulgan province and the ablative case marker (-aas) precedes Saihan sum are removed, the first alternative (1) turned into a non-grammatical sentence with no relation or connection between the two noun phrases. But, its grammatical alternative is shown below in (2).

(2) a. Bid Bulgan aimag-iin Saihan sum-aas irsen

b. We-NOM Bulgan province-GEN Saihan sum-ABL come-PST

c. We came from Saihan sum of/, Bulgan province.

Consequently, since these grammatical elements (-iin and -aas) do not occur in a merely single position, they play a significant role in connecting all the constituents in the sequences (phrase or clause), with each in their appropriate position.

\subsection{Previous literature}

Since the first compilation of Mongolian grammar in 1243, the number of studies on Mongolian case markers has reached many hundreds. These studies have generally followed the traditional grammatical approach. "The words of Mongolian have been classified on the basis of Indo-Tibetan linguistic approach since 14th century but RomanEuropean linguistic approach since 19th century" (Luvsanvandan.Sh 1968a:15).

The studies on the classifications of the case markers in Mongolian include those by Luvsanvandan.Sh. (1951; 1956; 1964), Tömörtogoo.D (1970; 1981), Byambasan.P (1996), Bazarragchaa.M (1997; 2005; 2008) and so on.

Mongolian language researchers including J.Street (1963), Bazarragchaa.M (1997; 2005; 2008; 2012) and Altanzagas.Ch. (1997) have focused on the semantic properties of the case markers. 
The alternatives of the case markers in Mongolian and the process of their changes were examined by Tömörtogoo.D (1968), Byambasan.P (1983) and Saruul-Erdene.M (2002).

Luvsanvandan.Sh $(1951 ; 1956 ; 1968 \mathrm{c})$ also did some research on the functions of the case markers in Mongolian.

The forms of the case markers in various Mongolian languages and dialects were further investigated by N. Poppe (1987) as a part of his comparative grammar.

There has been an another diametrical and questionable point of view about the presence vs. absence of the case system in Mongolian, first discussed by Lubsanjab.Choi $(1972 ; 1973)$ then late supported by Shagdarsuren.Ts (2002) and Tserenpil.D (manuscript; 2011) and others.

\subsection{Aim of study}

This paper aims to examine upon the Mongolian case markers from the syntactic point of view to denote a relation between the constituents in clauses and also, to encode any null constituents in order to generate some extended alternatives of the noun phrase (i.e. finite noun phrases) and relative clauses. This paper will not scrutinize the postpositions as aforementioned.

\subsection{Methodology of study}

For this study, some approaches of the Generative Grammar (GG) were found to be very useful. Namely, the Phrase Structure Rule and the X-bar theory are the fundamental principles to describe the syntactic structures or positions and hierarchical levels of various constituents or sequences by drawing tree diagrams. Also the Transformation Rule and the Empty Category Principle offered the capability to encode null constituents on the basis of their relation and their movement in the D-structure. The principle of the Full-Interpretation which "claims that there are no redundant elements in the structure of the sentence" (V.Cook \& M.Newson 1996:312) provided guidance on how to generate finite noun phrases and relative clauses. Similarly, other principles, rules and theories of the GG played their major and vital roles in this research paper.

\section{Denoting relations in noun phrases}

A Mongolian linguist has already noted that "Studying the element to denote any relation of the words in sentence through some different approaches is of significance for studying syntax" (Luvsanvandan.Sh 1965:216). Consequently, in order to study the internal structure of phrases, clauses and then sentences, the case markers which have a syntactic function to denote any relation need to be highlighted.

As a 'function word' or 'grammatical word' as mentioned above, the case markers, themselves, govern a noun phrase and connect it to nouns or its counterparts as well as verbs and adjectives to generate not only noun phrases but also verb phrases as in (3) and (4) or adjective phrases as in (5)-(7).
(3) a. üzeg-eer bichi-
b. üzeg-INST bichi-INF
c. to write with a pen.
(4) a. hü̈̈hdü̈d-tei toglo-
b. child-PLU COM play-INF
c. to play with children.
(5) a. mal-aar bayan
b. livestock-INST wealthy-INF
c. (to be) wealthy in livestock.
(6) a. öd (n)-öös höngön
b. feather-ABL light-INF
c. (to be) lighter than a feather.
(7) a. sum-shig hurdan
b. arrow-COMP ${ }^{1}$ fast-INF
c. (to be) fast as an arrow.

The two approaches used to generate noun phrases in the Mongolian language are shown below.

\subsection{Noun phrases generated through the parataxis}

This is an approach to generate some noun phrases through the way of directly connecting a noun as a head, and a modifier as a complement, as shown in (8)-(10).
(8) a. nogoon gerel
b. green-INF light
c. green light
(9) a. gurvan naiz
b. three-INF friend
c. three friends

(10) a. oyoson deel

b. sew-PST PART dress

c. a sewed dress

\footnotetext{
1-This abbreviation COMP (for the comparative case in Mongolian) is being used in this paper to distinguish it from COM (for the comitative case).
} 


\subsection{Noun phrases generated through the hypotaxis}

On contrary, this approach can generate numbers of the free and non-free structured noun phrases in Mongolian using the case markers for connecting both nouns as a head and a complement.

\subsubsection{Free structured noun phrases}

In this paper, the term free for this type of noun phrase is related to its internal structure. That is to say, both constituents of the noun phrases are connected by the genitive case marker as in (11) and comitative case marker as in (12) or some other elements with one of its constituents being the -hi morpheme (such as -dahi, -talaarhi, -urdahi, ömnöh, etc.), as in (13). In addition, the free structured noun phrase's most efficient property is its special capacity for syntactic transformations such as truncating vs. extending and changing vs. moving in their internal structure.

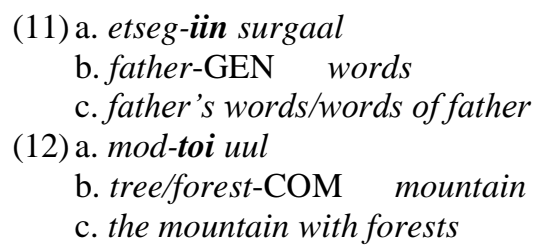

(13) a. Ulaanbaatar dahi salbar

b. Ulaanbaatar-DAT SUF branch

c. a branch in Ulaanbaatar

\subsubsection{Non-free structured noun phrases}

The free and non-free structured noun phrases show some important differences. The same external structures of the free and non-free structured noun phrases commonly connected by the genitive case marker cannot entirely describe their same internal structures. The reason is that some syntactic transformations in the non-free structured noun phrases are considerably limited in their internal structure.

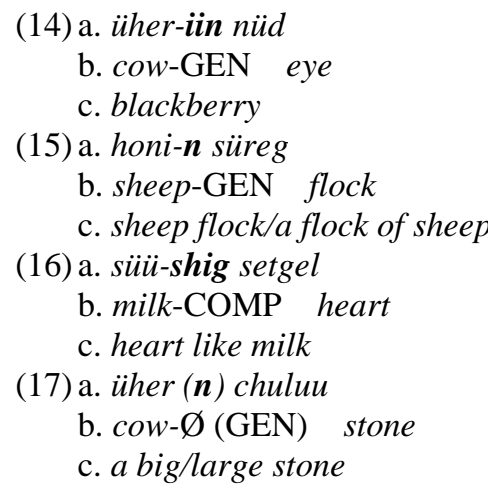

Namely, example (14) is a term while example (15) is a compound word. The noun phrase as in (16), whose constituents are connected by the comparative case marker, is also a collocation, but sometimes it can be in a null comparative case marker as in (17).

\section{Encoding null constituents}

One of the universal phenomena in all human languages is the truncation of its constituents in a phrase and clause. As an agglutinative language which belongs to the Altaic family of language, the truncation in Mongolian is a regular occurrence. Most of the Mongolian language researchers have explained it as a matter of language economy. According to Byambasan.P., truncating any noun in a phrase is a linguistic principle. So he postulated that the truncation of the noun mori (horse) in a noun phrase hurdniig unagch hü̈̈hdüïd (fast-ACC ride-PRE PART child-PLU $\rightarrow$ the children who are riding the fast (horses)) allows the grammatical, semantic and syntactic functions of the accusative case marker which governs the noun mori (horse) to transform into the adjective (hurdan (fast)) which is the complement of the noun mori" (Byambasan.P 1987:224).

Here again, I would like to emphasize the just aforementioned noun phrase hurdniig unagch hü̈̈hü̈̈d because such free structured noun phrases are a primary source of this research paper. In addition, the previous Mongolian language researchers, some of whose studies focused on nouns and noun phrases, have explained how the noun is truncated. They have also shown why the adjectives, numerals or participles can directly be governed by case markers in such noun phrases through other traditional linguistic theories and approaches which are the secondary source of this research. As a result, this research is being directed to answer the following three questions:

a. In which types of noun phrases can the head noun be truncated?

b. Why (not how) can the head noun in such noun phrases be truncated on one hand and encoded on the other?

c. Are all these phenomena, mentioned as questions, licensed by any case markers in Mongolian?

\subsection{Null constituents in noun phrase}

In Mongolian the noun phrase governs an adjective phrase, however, it is governed by a verb and a case marker to generate a verb phrase and postpositional phrase, respectively.

In the section 2.1, I have briefly touched upon the noun phrases generated through the parataxis. This type of noun phrases comprises a head noun which is modified by an adjective, numeral or participle as a complement and then 
develops a syntactic relation. In addition, these modifiers take case markers directly and govern other constituents on some occasions. This phenomenon has been described as follows, “... the noun which governs an adjective, numeral or participle can be truncated retaining its basic semantic and grammatical functions in the last three elements. In this case, these three elements can perform a role of the relevant noun which governs them and can take any case and possessive markers" (Modern Mongolian 2008:129).

Based on this observation, some questions might properly arose as to why the noun modified by the adjective, numeral or participle can be truncated; whether all the head word in phrases can be truncated as the noun does; and also whether the complement word can perform the role of the head word if it is truncated.

According to linguistic principle, I am tentatively proposing that the complement words can no longer receive any semantic and grammatical functions of the head words when they, in all phrases excluding the noun phrase, can be truncated. Furthermore, only on one occasion, however, it is acceptable for the noun phrase to truncate its head word when the relevant noun phrase itself is the complement of a postpositional phrase, or the noun phrase is governed by the case markers in Mongolian. From this assumption, let me present in detail the process of encoding the head noun in Mongolian - a kind of null constituents in the noun phrase in lower level, as the complement of a postpositional phrase in the higher one, through the case markers, as below.

\subsubsection{Constituents with adjective as complement}

In all human languages, the adjective is grammatically placed before and governed by a noun to generate a noun phrase. However, a special phenomenon in Mongolian commonly occurs in the S-structure and is described as follows, "When the adjective is used as a noun, it can be conversed by all noun markers (numeral, case and possessive)" (Modern Mongolian 2008:144). In this case, the English language licenses the or alan articles before and onelones pronoun after an adjective as in (18), whereas the Japanese -sa (さ) particle after the adjective is transformed into a noun as in (19).

\section{(18) a. I bought the white one}

b. I-NOM buy-PST the white one- $\varnothing$ (ACC).

(19) a. Kare wa kono tsukue no takasa wo hakatta

b. He-NOM this desk-GEN height-ACC measure-PST

c. He measured the height of this desk.

By contrast, Mongolian has a special phenomenon in that an adjective can take the -ni pronoun after the adjective is governed by a case marker as in (20).

(20) a. Byatshan hü̈̈ nomhon-iig ni unav

b. Little boy-NOM calm-ACC PRON ride-PST

c. A little boy rode a/the calm (-er/-est) horse.

In addition, there is another different occurrence in Mongolian in its S-structure: the adjective can directly develop the syntactic relation or operation not using such constituents as just mentioned above as in (21).

(21) a. Bid sar-iin sain-tai zolgoj, ödör-iin sain-iig hüleej suuna

b. We-NOM month-GEN fine-COM meet-PREPER, day-GEN fine-ACC wait-PRE PROG

c. We have (just) met the finest month and are waiting for the finest day (now) (according to the Lunar Calendar).

d.

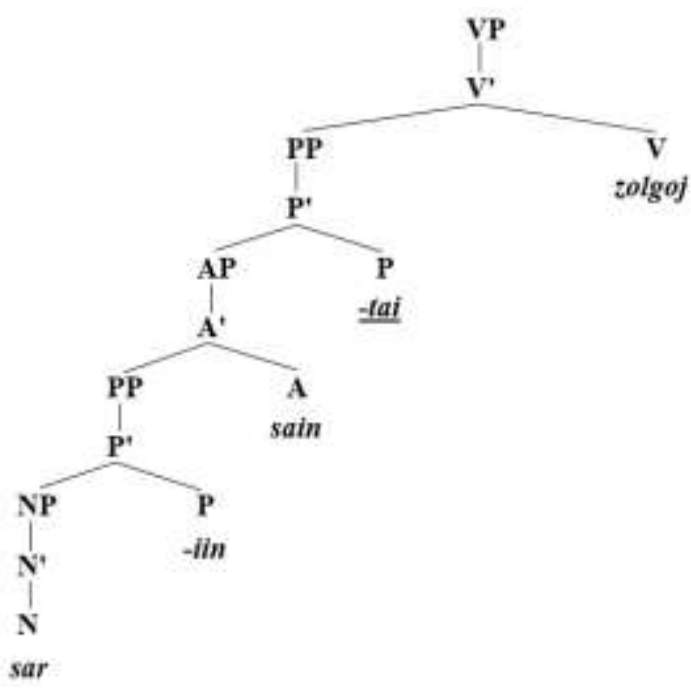

In fact, the (21) can be considered to be an inverse alternative of a kernel clause sain sartai zolgoj in (22).

(22) a. Bid sain sar-tai zolgoj, sain ödör-iig hüleej suuna

b. We-NOM fine month-COM meet-PRE PER fine day-ACC wait-PRE PROG 
$/ \$ /$

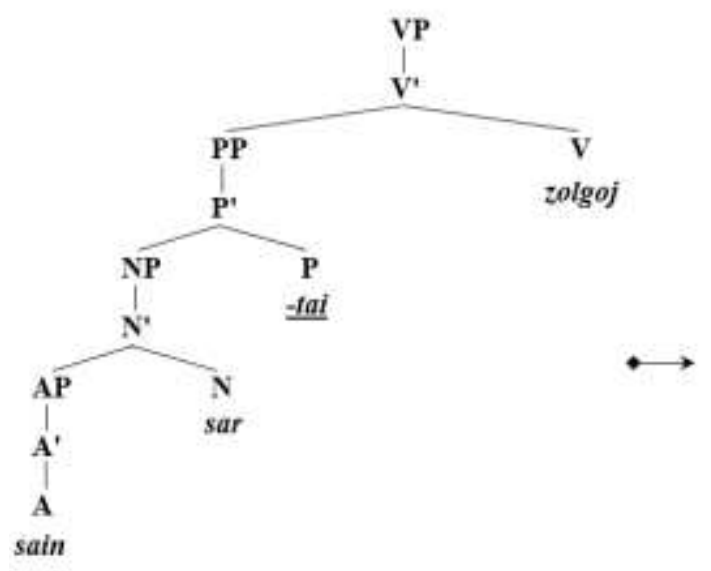

$/ \S \S /$

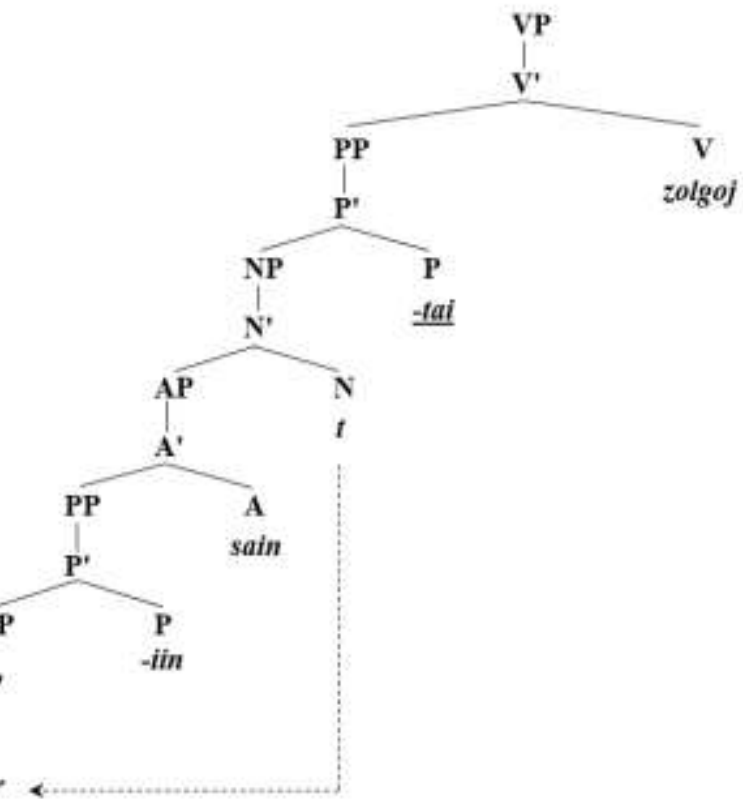

This is a movement of the complement noun sar of the postpositional phrase sain sar-tai.

Compared with the previous one in (22), the noun phrase sariin saintai zolgoj in (21) allows another type of its alternative to be extended. The sense of the case marker can encode its null noun 'tsag (time)' in (23).

(23) a. Bid sar-iin sain tsag-tai zolgoj, ödör-iin sain tsag-iig hüleej suuna

b. We-NOM month-GEN fine-INF time-COM meet-PRE PER, day-GEN fine-INF tsag-ACC wait-PRE PROG

c. We have (just) met the finest month and are waiting for the finest day (now).

d.

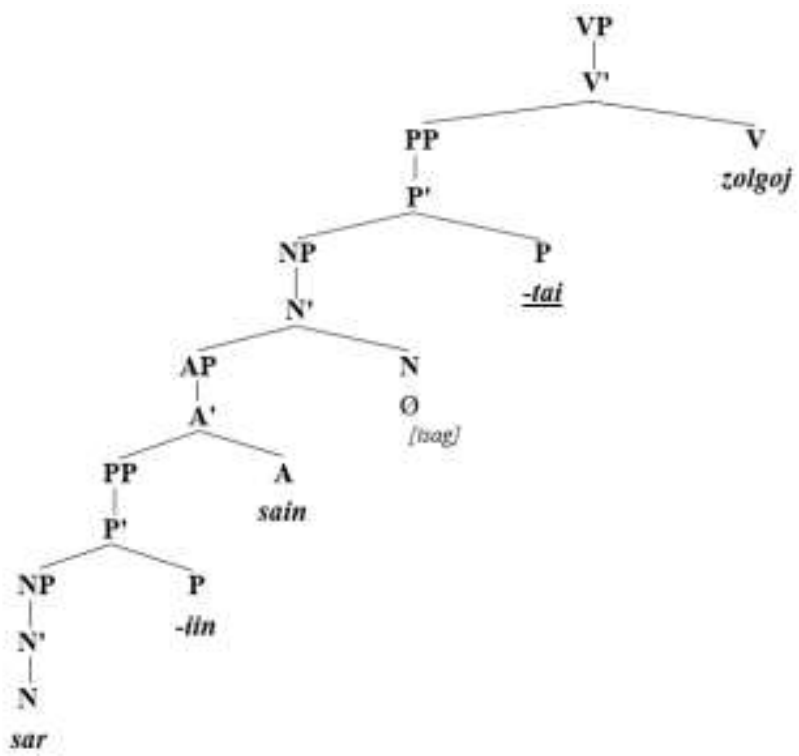

3.1.2 Constituents with numeral as complement

Grammatically and syntactically, the numerals, regardless of types, precede a noun as a quantifier which is another alternative modifier. All of them are governed by the head noun to generate a noun phrase at first and a postpositional phrase later. However, this kind of modifier sometimes generates the postpositional phrase by breaking the order aforementioned in its S-structure as in (24).

(24) a. Bat ter hoyor-toi (hamt) uuland avirlaa

b. Bat-NOM the two-COM mountain-DIR climb up-PST SIMP

c. Bat climbed up the mountain (together) with the two (boys) 
d.

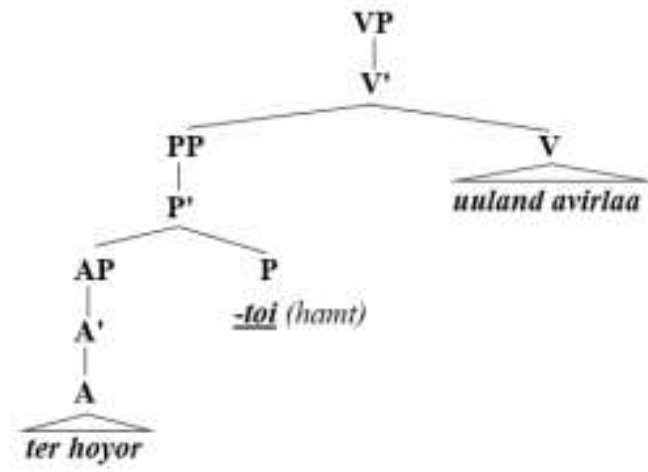

This clause can be extended by encoding a null noun hü̈̈ in its D-structure as shown in (25).

(25) a. Bat ter hoyor hü̈i-tei (hamt) uuland avirlaa

b. Bat-NOM these two boys-COM mountain-DIR climb up-PST SIMP

c. Bat climbed up the mountain (together) with these two boys.

d.

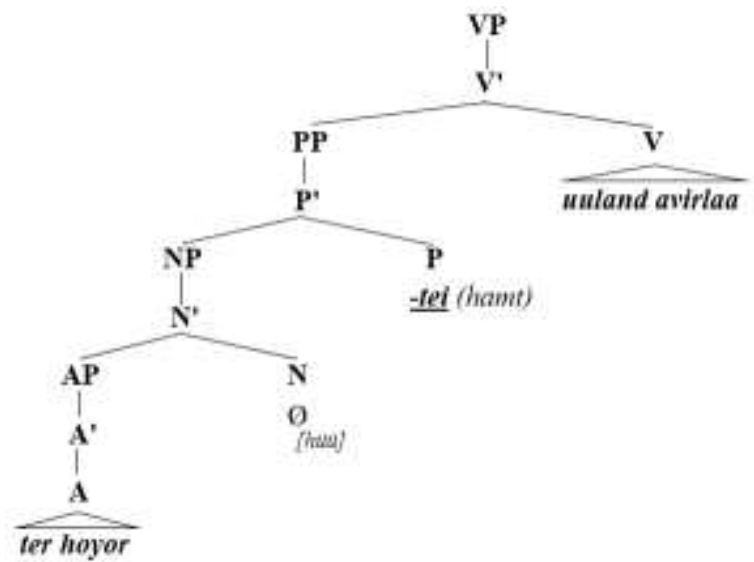

\subsubsection{Constituents with participle as complement}

In Mongolian, the participles are formed by some particles including "-san for past, -aa, -dag, -maar for present and $-h$ for future times" (Luvsanvandan.Sh 1968a:35) which provides a verb root to be governed by all the noun markers (case, numeral, possessive and postpositional) as in (26).

(26) a. Duulsan-iig huraaval erdem

b. Hear-PST PART ACC learn-COND knowledge-NOM be-

c. If you learn you've heard, it can be knowledge. If you learn (what) you've heard, it can be knowledge.

d.

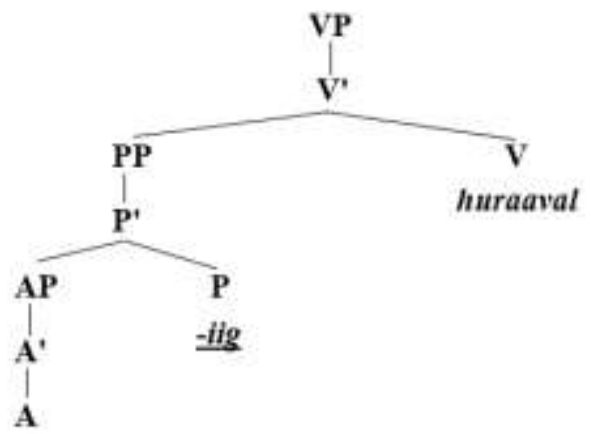

\section{dunlsan}

A verb root duula- in (26) takes both the past participle -san and the accusative case marker -iig. Systematically, no verb takes any case marker as the verb duula-(to hear) did here.

In accordance with the traditional linguistic approaches, this verb root transforms into a noun when coupled with the past participle -san. On contrary, the modern linguistic approaches have tended to interpret this phenomenon from a different point of view. I argue that this phenomenon does not depend on any participle particles but rather noun truncation. Since the participle particle like -san is not a derivational suffix that derives a noun from a verb root and the verb coupled with the participle particles can not only end a clause but can also modify a noun in Mongolian. As a result, it can be viewed that the verb with -san does not take the accusative case marker -iig directly. It modifies the null head noun or is governed by it and then generates a postpositional phrase as shown in (27). 
(27) a. Duulsan bïhen-iig huraaval erdem

b. Hear-PST PART all-ACC learn-COND knowledge-NOM be- $\varnothing$

c. If you learn whatever you've heard, it can be knowledge d. If you can learn, whatever you've heard will be knowledge.

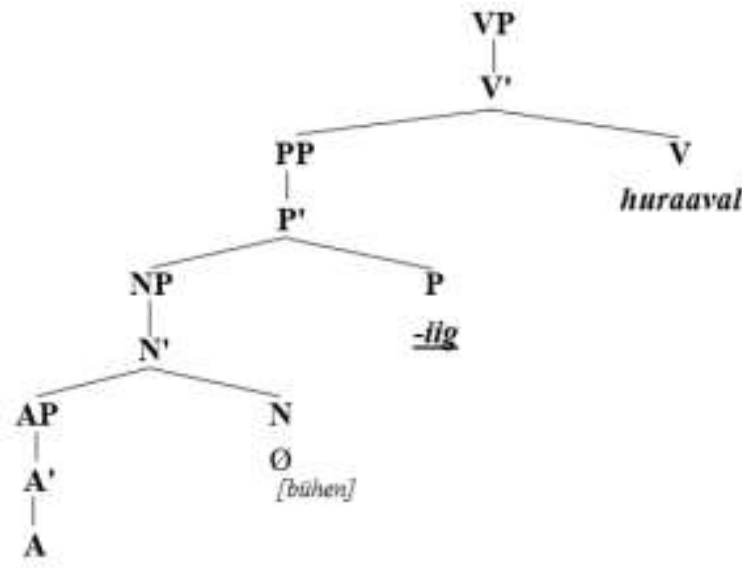

duulsan

In order to confirm this view, I would like to present another grammatical examples that a verb with participle particles must take a particle -koto (こと) when the relevant verb gets into a constituent of a postpositional phrase in Japanese - a related language of Mongolian.

\subsection{Null constituents in relative clause}

The Mongolian language is rich in free structured noun phrases that are generated by the genitive and comitative case markers in which the constituent is the -hi morpheme. The free structured noun phrases through the hypotaxis are the basic element in generating a relative clause.

3.2.1 Based on case markers

3.2.1.1 Genitive case marker

The genitive case marker in Mongolian is a quite specific element which "works harder than others to denote any relation" (Tserenpil.D 1990) due to its ambiguity. So, the free structured noun phrases in Mongolian as mentioned in sub-section 2.2.1, particularly the ones generated by the genitive case marker like etseg-iin surgaal in (11) are the main object of this research since their internal structure can syntactically be transformed.

However, the non-free structured noun phrases as mentioned in (14)-(17), limit such syntactic transformations in their internal structure. For example, the üher-iin nüd in (14) is a fruit name generated by the combination of two nouns üher and nüd which are connected by the genitive case marker -iin. As this is a type of noun phrase on one hand but a term on the other, no constituents in this phrase can be added, truncated, changed or moved in its internal structure as in (28). Such alterations can only be added to its external structure.
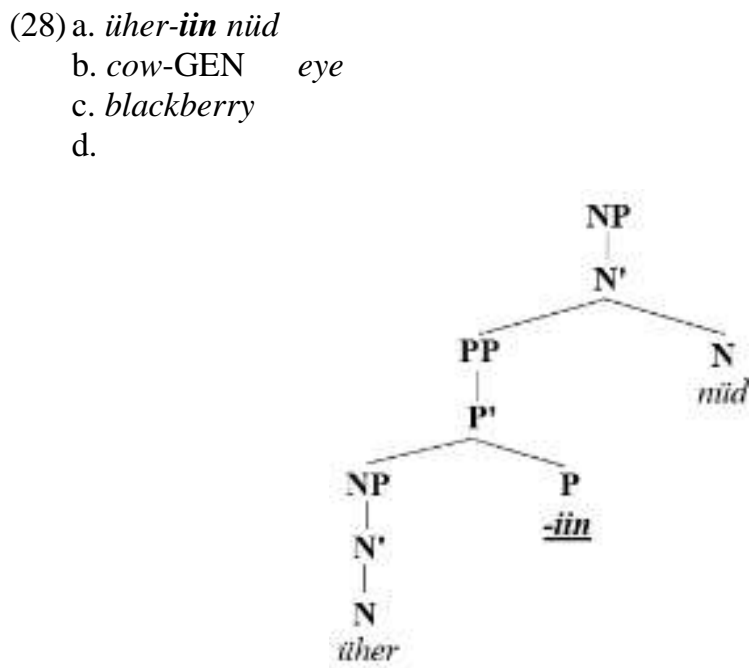

Even though, the noun phrases like aav-iin mori in (29), generated through the hypotaxis are quite different in their internal structures. So, that means they accept any syntactic transformations in either their internal or external structures.

(29) a. aav-iin mori

b. father-GEN horse

c. my father's horse la horse of my father 
d.

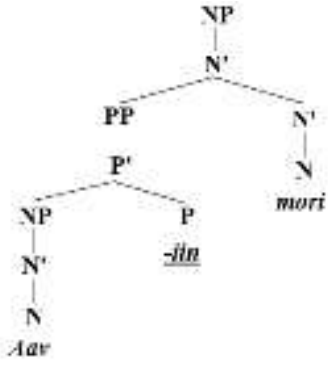

One of these transformations is extending a phrase that generates a relative clause in a way that encodes null constituents in the phrase. Consequently, this free structured noun phrase aav-iin mori in (29) can be viewed to be a miniature alternative of a relative clause since the null verb or predicate can be encoded as in (30).

(30) a. aav-ïn hudaldaj avsan/unaj yavaa/uyasan mori

b. father-GEN buy-PST PART/ride-PRE PROG/train (for race)-PST PART ${ }^{2}$ horse

c. the horse (that) my father (has) bought/is riding/(has) trained

d.

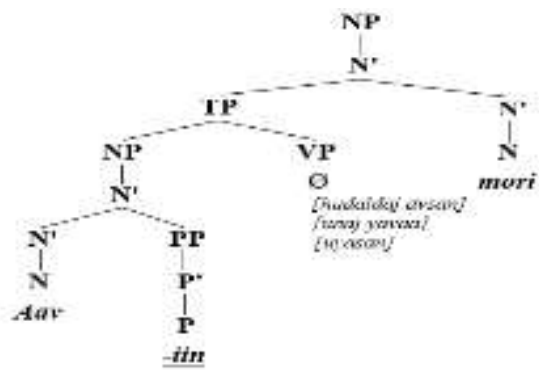

The next example is Erdenet-iin galt tereg in (31) whose external structure appears to be the same as the previous phrase aav-iin mori in (29).

(31) a. Erdenet-iin galt tereg

b. Erdenet (city)-GEN train

c. Train tolfor Erdenet (city)

d.

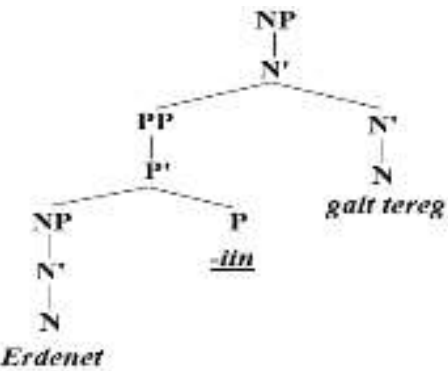

Similarly to the example (29), the Erdenet-iin galt tereg in (31) is generated by the same genitive case marker to connect both nouns in the phrases. But there is a big difference observed in their internal structures. The $\theta$-theory helps to encode its null constituent chiglel-d yavah as shown in (32).

(32) a. Erdenet-iin chiglel-d yavah galt tereg

b. Erdenet (city)-GEN direction-DAT depart-PREPART train

c. the train which departs for Erdenet city

d.

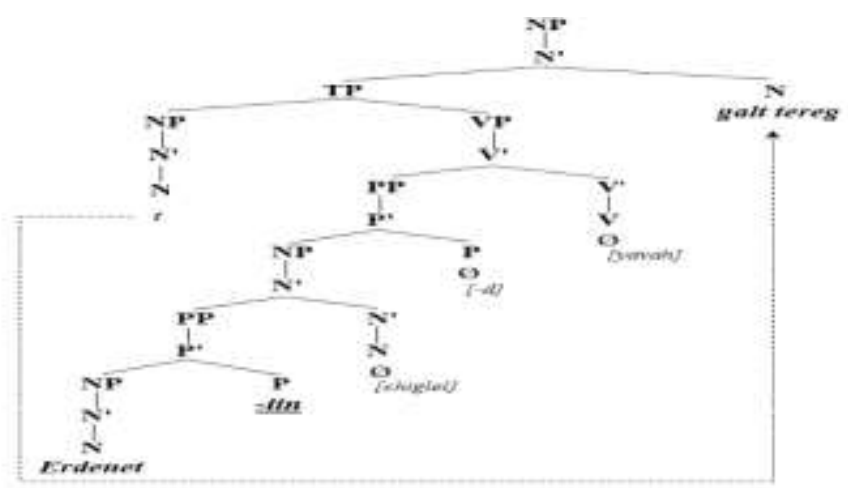

\footnotetext{
${ }^{2}$ As an agglutinative language, Mongolian allows the past particles of verbs to be used as particles of all past tenses in English.
} 
Reviewing and comparing the three noun phrases in (28), (29) and (31), the üher-iin nüd in (28) cannot be transformed in its internal structure as it is a term which expresses a definite sense, whereas the aav-iin mori in (29) and the Erdenetiin galt tereg in (31) allow more syntactic transformations and extended alternatives as they are the free structured noun phrases which express some general and abstract senses.

But the latter two phrases have some specific differences in their internal structures for the syntactic transformations.

As for the aav-iin mori in (29), the aav is the complement of the head noun mori in its S-structure. However, in the example (30) - an extended alternative of the noun phrase of which the null constituent has been encoded, the aav is a genitive-marked subject of the relative clause which modifies the head noun mori in its D-structure. This transformation is based on a principle that the subject of the relative clause is formed by not only the nominative but also genitive and accusative case markers in agglutinative languages like Mongolian and Japanese (Luvsanvandan.Sh 1968c; K.Hiraiwa 2000; Dashdavaa.V 2012; Zayabaatar.D et al, 2016).

Even though, the Erdenet in the noun phrase Erdenet-iin galt tereg in (31) is the complement of the postpositional phrase in the lower level - a constituent of the verb phrase in the relative clause which modifies the head noun galt tereg as in (32).

\subsubsection{Comitative case marker}

The comitative case marker (-tai) which expresses five (J.Street 1963:198-9) and eight (Bazarragchaa.M 2005:146) senses, is placed in a definite position in a clause, requires an appropriate verb, and commonly denotes noun and verb $(\mathrm{N}+\mathrm{V})$ relation. For instance, a sense of this case marker hamt or tsug (with or together with) denotes the $\mathrm{N}+\mathrm{V}$ relation, even though, with a sense of possessing (with or having), the -tai can denote the $\mathrm{N}_{1}+\mathrm{N}_{2}$ relation.

Fascinated by a questionable issue on whether the -tai is the comitative case marker or not, I have diachronically studied the internal structure of the noun phrases with this -tai case marker based on its positions in the clause - its external domain. Many researchers have noted that this -tai was a derivational suffix to form an adjective from a noun root in the Middle Mongolian period. But, according to this study, all the adjectives derived by the -tai in "the Secret History of the Mongols" - an invaluable monument of the Middle Mongolian history, culture, language and literature, etc. can be classified into two parts depending on abstract and concrete noun roots. On occasions when these abstract noun roots take the -tai, the abstract adjectives are derived which cannot denote any relation. On the contrary, the concrete noun root forms the adjective which denotes a relation between the two nouns. On this basis, I have concluded that "the concrete sense of the -tai whose function is to denote a relation, is the origin of the comitative case marker in Modern Mongolian" (Otgonsuren.Ts 2012). These phenomena can be illustrated through the following example.

The amjilt-tai in (33) is one example of the abstract adjectives.

(33) a. amjilt-tai ajil hereg

b. success-SUF business

c. a successful business

d.

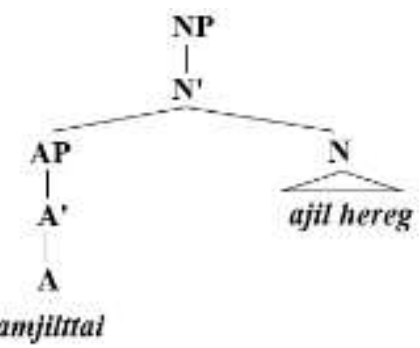

The noun phrase generated by the combination of an adjective and a noun, through the parataxis does not allow to encode a verb for a relative clause like ones in the (29) and (31), because the adjective in (33) turns into an adverb and its basic form and position are changed as shown below (34).

(34) a. amjilt-tai (-aar) yavj bui ajil hereg

b. success-SUF Ø(SUF) run-PRE business

c. the business which runs successfully

d.

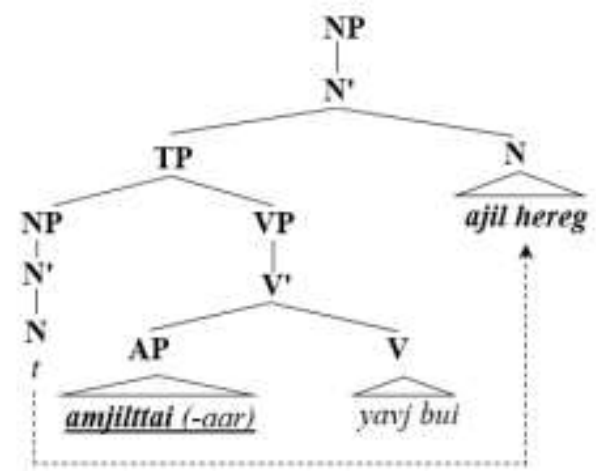


When any extended alternatives are generated by the adjectives derived from an abstract noun as in (34), its internal structure or fundamental relation must be broken. So, this structure in (34) cannot be viewed to be caused by the noun and noun relation.

Instead, as the -tai connected to a concrete noun root like sü̈̈ and kofe in (35) denotes a relation between both nouns, thus, the -tai can be changed by a single verb with a sense of having or possessing as well as a verb phrase depending on its context to generate a relative clause as in (36).
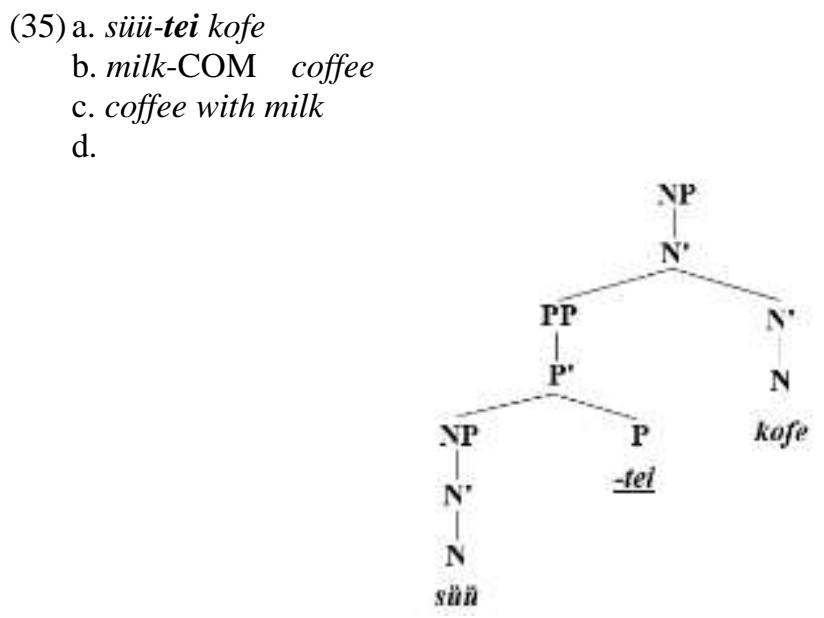

The example in (36) is an extended alternative of the noun phrase and particularly its tree diagrams in (36d), show which case markers, depending on the head verb of the relevant phrase, the complement noun can be governed by when it generates a verb phrase.

(36) a. sü̈ïtei nairuulsan kofe

b. milk-NOM have-PRE PART/milk-COM mix-PST PART coffee

c. the coffee with/which is mixed with milk

d.

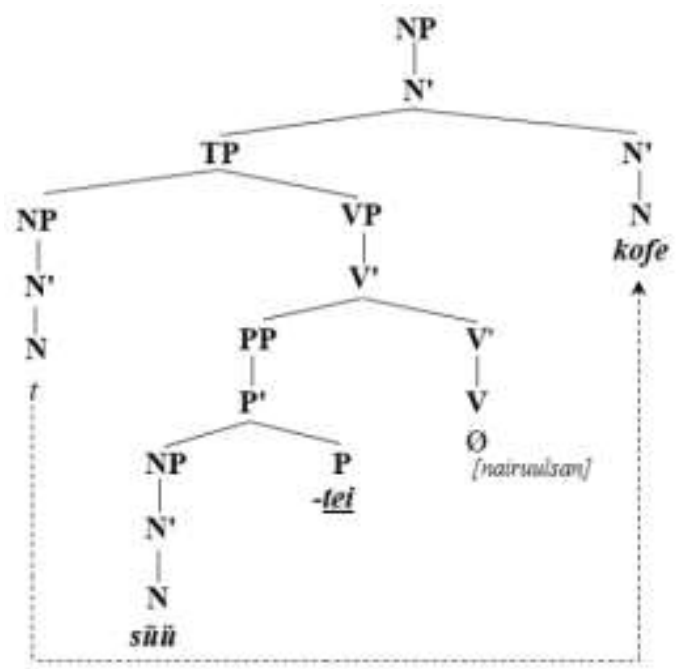

\subsubsection{Based on an element with -hi morpheme}

Except for some case markers, there are some other elements with -hi morpheme in Mongolian such as dahi, deerhi, doorhi, urdah, ömnöh, ardah, hoidoh, terteeh and so on, which denote a relation in sentence. One of them is -dahi - as viewed "one of which constituents is the dative case marker and another is -hi" (Tserenpil.D 1990). Why this element is being emphasised here is related to its sense of existing as in (37).

(37) a. ogtorgui-dahi odod

b. sky-DAT SUF star-PLU

c. the stars in the sky

d.

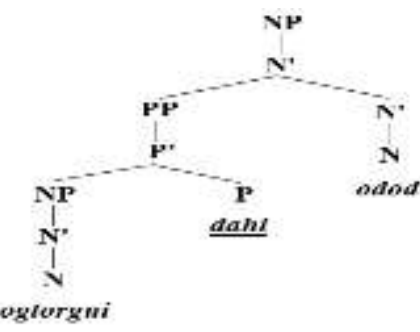


The dative case marker $(-d)$ requires a verb relation systematically but a noun relation (or $\mathrm{N}_{1}+\mathrm{P}+\mathrm{N}_{2}$ ) regularly on the only occasion, when it takes the -hi morpheme. But according to Tserenpil.D, "this - $h i$ morpheme has kept its grammatical meaning which change its verbal syntagmatic relation into the noun one for all the periods of the Mongolian language" (Tserenpil.D 1990:13). As a result, the sense of the -dahi is of great importance in encoding the verb in such noun phrases as in (38).

(38) a. ogtorgui-d baigaa/gyalalzah odod

b. ogtorgui-DAT be/sparkle-PRE PART star-PLU

c. the stars which are/sparkle in the sky

d.

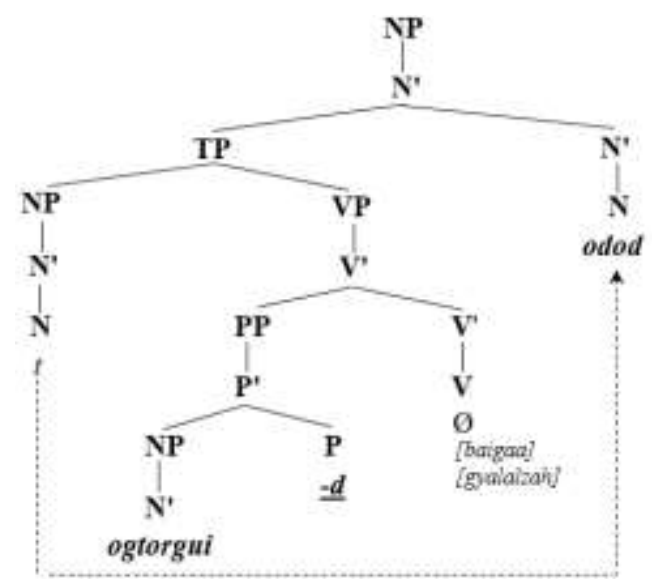

\section{Conclusion}

"At the deep level, a sentence structure is represented in an abstract way" (D.Crystal 1997:98). According to the present research, the genitive case of Mongolian as an agglutinative language has a special capacity to denote not only complement but also adjunct relations in clauses. Based on the grammatical system of generating noun phrases through the parataxis and hypotaxis in Mongolian, I offer the following conclusions.

1. When the noun phrase itself which is generated through the parataxis is the complement of a postpositional phrase, the head noun of the relevant noun phrase can be truncated. So, this reveals that it is rather possible to encode the truncated noun or the null head noun, and then to generate a finite noun phrase on the basis of the senses of the case marker that is the head word of the postpositional phrase. That explains why the modifiers of the noun including adjective, numeral and participle directly take various case markers when they are a constituent of a verb phrase, is related to the fact that not the modifiers themselves but their head nouns take these case markers in their null forms as shown in (39).
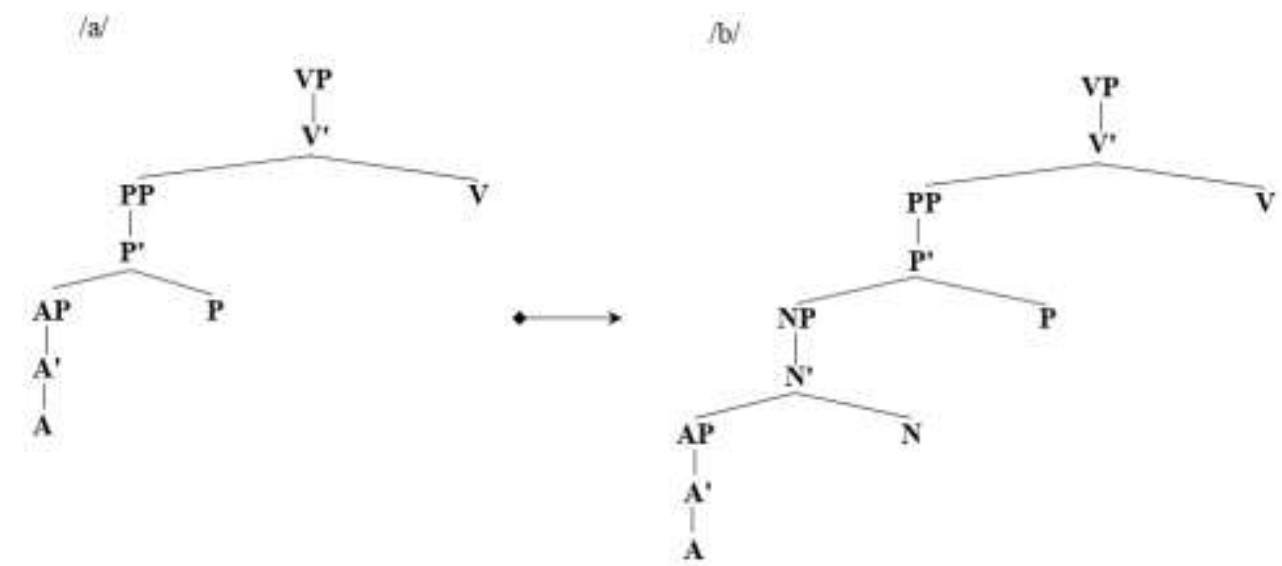

2. Most of the noun phrases through the hypotaxis, are generated by the genitive case marker (-iin) but some of them are generated by the comitative case marker (-tai) and by another element which consists of the dative case marker $(-d)$ and the morpheme $-h i$. However, the internal structures of these types of noun phrases show that different mechanisms initiate their generating in Mongolian. So I argue that encoding the null constituents in these types of the noun phrases provides a catalyst to generate their finite or extended alternatives - the relative clauses. In this case, there are major differences of the complement nouns observed at the sentence level. That is, if the complement noun of the postpositional phrase which is a constituent of the noun phrase as in (40a) works as the subject of the relative clause which modifies the head noun in a noun phrase, it is in a higher level as in (40b) but, as a complement noun of the postpositional phrase in a verb phrase, it is placed in a lower level as in (40c). 

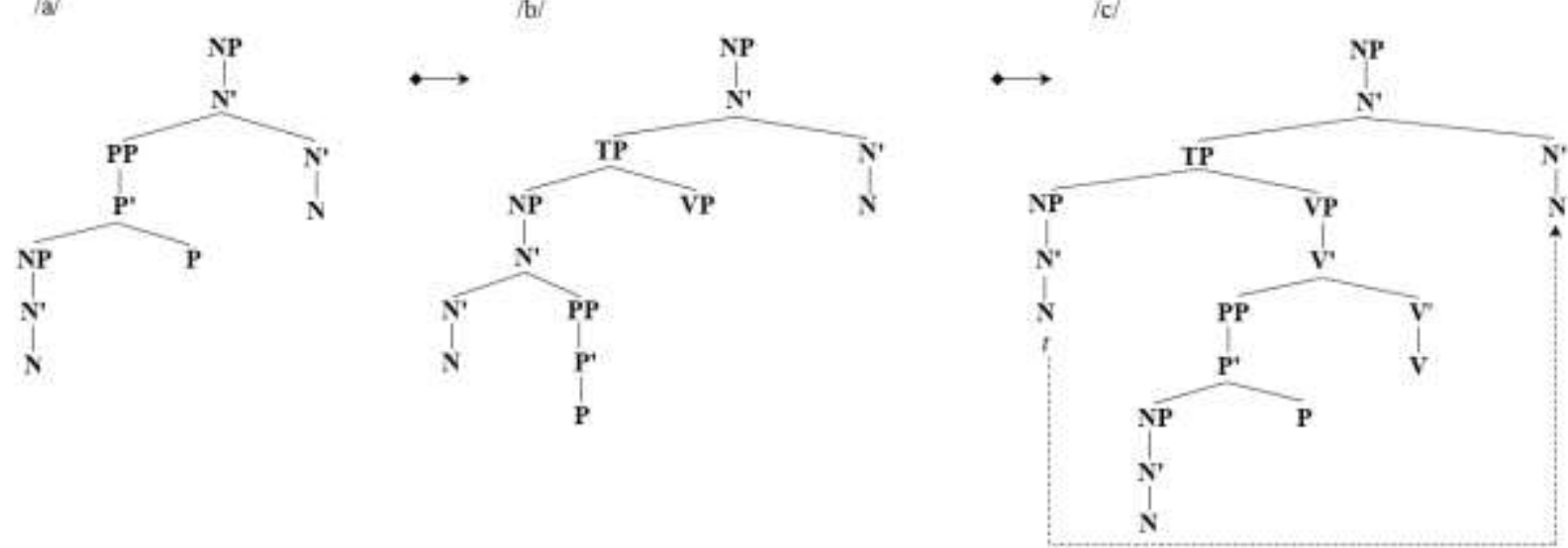

3. In all the syntactic transformations such as truncating, extending, changing and moving in Mongolian, this grammatical element - case markers, particularly the genitive case marker, perform a great and key role. That is, case markers illustrate that Mongolian has not only agglutinative but also abstract structures.

\section{References}

In English

Andrew, R. (1998). Syntax: A minimalist introduction. Cambridge University Press.

Dashdavaa, V. (2012). A study on case in English and Mongolian. A dissertation submitted to Kookmin University. Seoul. Korea.

David, C. (1997). The Cambridge encyclopedia of language. II ed. Foreign Language Teaching and Research Press and Cambridge University Press. Beijing.

Jim, M. (2002). An introduction to English syntax. Edinburgh University Press.

John C. S. (1963). Khalkha structure. Indiana University. Bloomington: Mouton \& Co., The Hague. The Netherlands.

Ken, H. (2000). On nominative-genitive conversion. MIT Working Papers in Linguistics, 39, 66-125.

Lubsanjab, C. (1973). On the case in Mongolian. The II International Congress of Mongolists. Vol I. Ulaanbaatar.

Nicolas, P. (1987). Introduction to Mongolian Comparative Studies. Helsinki.

Noam, Chomsky. (2002). Syntactic structure. 2nd edition with an Introduction by David W.Lightfoot. Berlin and New York: Mouton de Gruyter.

Vivian, Cook and Mark, Newson. (2000). Chomsky’s universal grammar: An introduction. 2nd edn. Foreign Language Teaching and Research Press and Blackwell Publishers Ltd. Beijing.

Zayabaatar, D., Dashdavaa, V., Enhjargal, D and Onon, Ts. (2016). Genetive case-marked subject in Modern Mongolian. Advances in Language and Literary Studies, 7(2).

\section{In Russian and Mongolian}

Altanzagas, Ch. (1997). On the “-TAI" morpheme in Mongolian. The research papers №9 (126). School of Mongol Studies. Ulaanbaatar.

Bazarragchaa, M. (1997). About the etymology of Mongolian case inflections. The research papers №8 (116). NUM. Ulaanbaatar.

Bazarragchaa, M. (2005). Syntax of the Mongolian language. Ulaanbaatar.

Bazarragchaa, M. (2008). Studying the case inflections of Mongolian as their form or senses and stative or dynamic pecularities. The Mongol Studies. Vol 28 (294). School of Mongolian Language and culture. NUM. Ulaanbaatar.

Bazarragchaa,M. (2012). Some issues on Mongolian linguistics. Ulaanbaatar.

Byambasan, J. (1996). A possibility of classifying the inflections in Modern Mongolian as their relations. On issues of the Mongolian language theory and structures. The Institute of Language and Literature. Ulaanbaatar.

Byambasan, J. 1983 (2006). On a version of accusative case in Modern Mongolian. On issues of the Mongolian language theory and structures. The Institute of Language and Literature. Ulaanbaatar.

Byambasan, J. 1987 (2006). A specialty of noun in Mongolian. On issues of the Mongolian language theory and structures. The Institute of Language and Literature. Ulaanbaatar.

Luvsanvandan, Sh. 1951 (2010). Mongolian grammar - 1. The anthology of the works by Academician Luvsanvandan.Sh. Vol.2. Ulaanbaatar.

Luvsanvandan, Sh. 1956 (2010). Textbook for Mongolian grammar. The anthology of the works by Academician Luvsanvandan.Sh. Vol.3. Ulaanbaatar. 
Luvsanvandan, Sh. 1964 (2010). The direct and oblique cases in Modern Mongolian. The anthology of the works by Academician Luvsanvandan.Sh. Vol.7. The studies on the morpheme, word and sentence in Mongolian. Ulaanbaatar.

Luvsanvandan, Sh. 1965 (2010). The relation of the words in sentence. The anthology of the works by Academician Luvsanvandan.Sh. Vol.7. The studies on the morpheme, word and sentence in Mongolian. Ulaanbaatar.

Luvsanvandan, Sh. 1968a (2010). About the issues on classifying the Mongolian words. The Anthology of the works by Academician Luvsanvandan.Sh. Vol.7. The studies on the morpheme, word and sentence in Mongolian. Ulaanbaatar.

Luvsanvandan, Sh. 1968b (2010). About the issues on morphemic theory. The anthology of the works by Academician Luvsanvandan.Sh. Vol. 9. The issues on linguistic theories. Ulaanbaatar.

Luvsanvandan, Sh. 1968c (2010). The words and inflections in Modern Mongolian. The anthology of the works by Academician Luvsanvandan.Sh. Vol.5. The structure of Modern Mongolian. Ulaanbaatar.

Lubsanjab, Choi. (1972). About case system in Mongolian. The Research Papers. № 41. NUM. Ulaanbaatar.

Mongolian Linguistics. (2008). The Mongolian State University of Pedagogy. School of Mongol Studies. Department of Mongolian linguistics. Ulaanbaatar.

Otgonsuren, Ts. (2012). Grammatical comparison of the suffix "-TAI" and its alternatives in the "Secret History of the Mongols". Acta Mongolica Research papers from the Institute for Mongol Studies, NUM. Vol 12(383). pp137-151. Ulaanbaatar.

Purev-Ochir, B. (1988). The system of syntactic connection in Modern Mongolian. Ulaanbaatar.

Saruul-Erdene, M. (2002). The morphological changes of Mongolian inflections. Doctor's Dissertation. Ulaanbaatar.

Shagdarsuren, Ts. (2002). About the issues on Mongolian cases' terms and their origins. Acta Mongolica. Centre for Mongol Studies. NUM. Vol.1 (182). Ulaanbaatar.

Tömörtogoo, D. 1968 (2002). Some alternatives of Mongolian accusative case. About the issues on Mongolian linguistic theory and history. Ulaanbaatar.

Tömörtogoo, D. 1970 (2002). Classified case inflections in Mongolian linguistics. About the issues on Mongolian linguistic theory and history. Ulaanbaatar.

Tömörtogoo, D. 1981 (2002). The historic tradition and theoretical background of Mongolian linguistics. About the issues on Mongolian linguistic theory and history. Ulaanbaatar.

Tömörtogoo, D. 2001 (2002). About the issues on the structures of noun to denote a place relation. About the issues on Mongolian linguistic theory and history. Ulaanbaatar.

Tserenpil, D. (1990). On a special inflectional morpheme in Modern Mongolian. The research papers, 102(4). NUM. pp309-317. Ulaanbaatar.

Tserenpil, D. (1997). The structural - functional systems of relational morphemes in Modern Mongolian. Doctor's Dissertation. Ulaanbaatar.

Tserenpil, D. (manuscript). Case: the issues on a relationship in the Mongolian and English languages. Ulaanbaatar.

Tserenpil, D. (2011). The universal grammar and Mongolian. Ulaanbaatar. 